\title{
From unplanned to planned agricultural use: making an asset out of wastewater
}

\author{
Jules B. van Lier • Frans P. Huibers
}

Published online: 15 December 2009

(C) The Author(s) 2009. This article is published with open access at Springerlink.com

\begin{abstract}
Urban wastewater is increasingly used for agricultural production, particularly in those areas where access to fresh water resources is limiting. Depending on the prevailing institutional arrangements, this agricultural use is planned or unplanned. If planned, a general policy is to minimise health risks and environmental pollution, leading to an often centralised collection of the city's sewage, followed by primary, secondary and further treatment until the prevalent discharge effluent use standards are met. If society can afford them, advanced treatment technologies are installed, backed by a well functioning institutional infrastructure. In contrast, in less prosperous countries the agricultural use of wastewater is driven by the high needs for water and the absence of affordable fresh water resources along with insufficient financial means to construct treatment systems and distribution networks that comply with the official regulations. Combined with a poor institutional framework, this results in unplanned and unguided direct or indirect use of raw, partially treated or diluted wastewater. In an effort to mitigate health and environmental problems, we propose using a reverse water chain design approach, in which the ultimate fate of the water is the basis for the design of conveyance and treatment facilities.
\end{abstract}

Keywords Design - Developing countries · Peri-urban agriculture - Reverse water chain · Urban water management · Wastewater irrigation · Wastewater treatment · Water quality

\footnotetext{
J. B. van Lier

Faculty of Civil Engineering and Geosciences, Department of Water Management, Section Sanitary Engineering, Delft University of Technology, P.O. Box 5048, 2600 GA Delft, The Netherlands e-mail: j.b.vanlier@tudelft.nl

J. B. van Lier

Department of Water and Sanitation, Unesco IHE Institute for Water Education, P.O. Box 3015, 2611 AX Delft, The Netherlands

F. P. Huibers $(\bowtie)$

Irrigation and Water Engineering Group, Wageningen University, P.O. Box 47, 6700 AA Wageningen, the Netherlands

e-mail: frans.huibers@wur.nl
} 


\section{Introduction}

In many developing countries, water is becoming a limiting factor and wastewater is considered an alternative water resource for agricultural production. After all, a small town of 100.000 people produces sufficient wastewater to cultivate an area of up to 100 hectares, all year around, assuming a per capita urban water consumption of 80-100 1/day. The major constraint in irrigation with wastewater is the hazards that it poses to human health. Environmental issues also play a role, such as the fate of nutrients outside the irrigation season and the effects of micro-pollutants, although these problems are worse if all the wastewater is directly discharged.

In industrialised countries these constraints are addressed by implementing extensive treatment systems that eliminate the mentioned health and environmental hazards (e.g. Asano 1998), in line with a conventional urban water chain approach (Huibers and van Lier 2005), in which water is centrally distributed to houses and industrial complexes and the produced wastewater is subsequently collected by sewerage systems. The treatment plant is the targeted location for intercepting the water quality in order to meet regulations for discharge or effluent use.

By directly linking a treatment plant to an agricultural production site, the required treatment technology needs reconsideration, taking into account the effluent characteristics of actual concern in agricultural use (Martijn and Huibers 2001).

- $\boldsymbol{C O D / B O D}$ levels can be more relaxed than the generally applied stringent values, particularly considering the positive effect of organic matter on soil structure in agricultural fields that are deprived of organic matter.

- Nutrients are resources that can beneficially be used by farmers and should not be removed. However, off-season or whenever nutrients are in excess, periodic nutrient removal could be a strategy in the treatment system (Kassab et al. 2007). Depending on the crops that are grown, the available nutrients are sufficient for crop cultivation, reducing farmer's expenditure on artificial fertilizers (Boom et al. 2007). Balancing nutrients in the field to support crop requirements, while avoiding environmental pollution, gives important incentives to reconsider the wastewater treatment techniques used, as well as the irrigation water management system.

- Pathogens removal is considered an important step in the treatment process. However, the problem with pathogens can also be addressed at other levels in the water chain or in the food chain as is discussed in this paper.

- Solids could have a negative impact on irrigation, particularly in pressurized systems. A step to remove might be included in the wastewater treatment system, or alternatively in the irrigation network through additional filtration or settling steps, e.g. in storage basins.

- Heavy metals are generally not considered when treating domestic wastewater, as they are generally not in. However, this might be different in developing countries, certainly where wastewater origin is not always well defined. When coupled with agricultural use, care should be taken since heavy metals accumulate in the soil. A high degree of heavy metal removal is expected when an anaerobic treatment step is included, causing precipitation of (bivalent) metal-sulphides (van Lier 2008).

- Salinity of the effluent is not considered in conventional treatment, because salts cannot be removed by plain technologies, but it is of utmost importance if the effluent is used in irrigation. This parameter is determined by the sources of wastewater and the level of evaporation in the treatment process. 
If an irrigation system fully depends on effluent as a water source, operational storage of effluent is needed. This storage facility would be part of the overall development and should be designed such as to play a role in (post-) treatment.

\section{The conventional water chain approach}

Figure 1 depicts a typical representation of a conventional urban water management chain, in which upstream water source and downstream effluent use are de facto considered as black boxes. Drinking water arrives at the households at the highest quality. From here, the used and contaminated water is collected in a sewerage system, where rainfall runoff and other pollutants are added. Before the collected sewage is discharged into the environment or used in agriculture, treatment is required to reach agreed standards. Scientific insights and public perception of potential risks that can occur as a result of using treated wastewater, lead to public demands to tighten the quality criteria, requesting efficiencies for wastewater treatment at the highest level.

In addition to numeric values obtained from environmental and human health studies, standards are also getting stricter as a result of emotional debates and legal liability of those producing the treated water. The ever-increasing required treatment efficiencies with regard to pathogens, micro-pollutants and nutrients in the arid areas of industrialised countries such as parts of the USA and Israel are illustrative in this respect (see Shuval et al. 1997; Rose 2007). In industrialised countries, more and more technologies are under development that could be used to achieve this goal. The costs for infrastructure, operation and maintenance, and institutional guidance are increasingly higher, yet covered by tax income or are invoiced to the specific polluter in the chain. Shuval et al. estimated that based on the USEPA/USAID guidelines, the costs of wastewater treatment to prevent a single case of Hepatitis A, would be approximately US\$ 30 million. This, of course, by far exceeds the costs for curing a patient who has fallen ill. Moreover, Blumenthal and Peasy (2002) state that there is no epidemiological evidence proving the need to define the guidelines more strictly than the WHO values of 1989 (WHO 1989).

In less prosperous countries, civil and institutional infrastructure is poorly developed and sometimes largely lacking. Nonetheless, the need for the efficient use of water is huge,

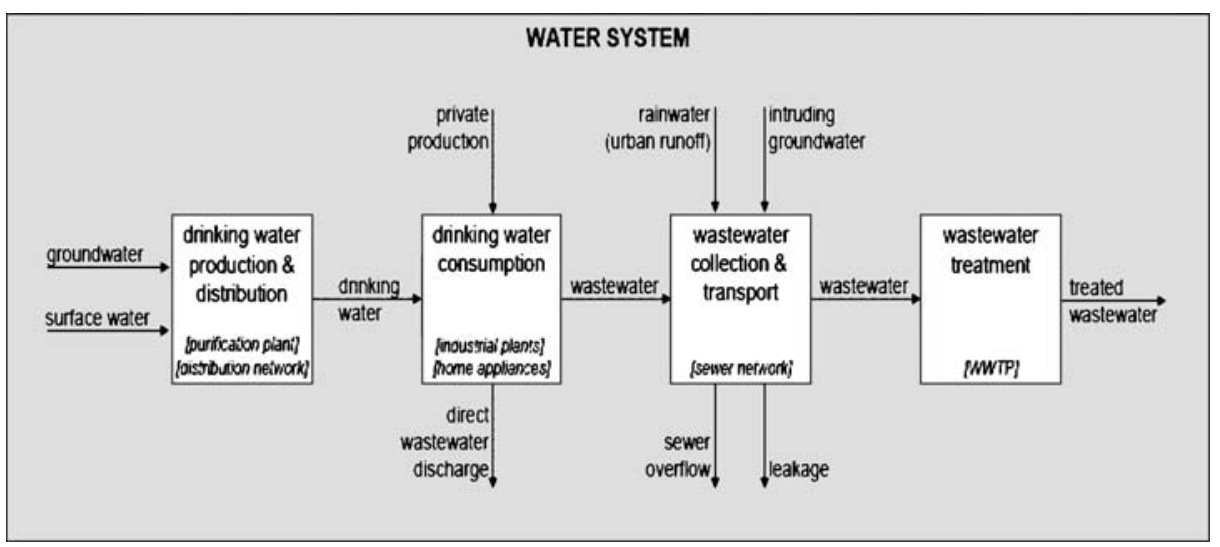

Fig. 1 Schematic representation of the conventional urban water chain (Bots 2008) 
particularly in water stressed countries. Yet, the general concern about environmental and human health issues related to the use of effluents in irrigated agriculture is apparent in each country. Official governmental regulations often demand stringent wastewater treatment requirements, especially when the effluent is used for producing edible crops.

As financial means are by far insufficient to construct and maintain the required infrastructure, this creates a paralysed situation, which aggravates when the role of agriculture for city food production and for providing a livelihood for the urban and periurban farmers, remains unrecognised. The net result is an unofficial tolerance of the uncontrolled usage of polluted water as can be observed in many countries around the globe. The total agricultural area irrigated with partly or untreated wastewater exceeds 20 millions ha in over 50 countries (van der Hoek 2004).

As discussed, costs of distribution, collection, treatment and logistic management in a conventional urban water chain are extremely high and the required infrastructure needs a long period of time for development. The sewerage system in the Netherlands, with a population of 16 million, has a total length of $109,000 \mathrm{~km}$, which is $7.5 \mathrm{~m}$ per person (Stichting Rioned 2006). The yearly maintenance costs of this sewerage system, including the treatment plants, is approximately $€ 150$ (US\$ 200) per capita. In addition to the resources required to construct the civil and electro-mechanical works, energy requirements for pumping and wastewater treatment are far beyond the budget of most developing countries. Accepting that the conventional approach makes no sense for many of the less prosperous countries, alternative strategies should be searched for which do not compromise on the environmental and human health constraints.

\section{The reverse water chain approach}

In a reverse water chain approach, the quantitative and qualitative water requirements of the final users are taken as the starting point for designing the upstream civil and institutional infrastructure. As a consequence, the type and functionality of the wastewater treatment system is determined by the farmer's need rather than by governmental legislation for wastewater discharge.

Such a reverse approach leads to design criteria that differ from those in a conventional design:

- The required effluent characteristics (pathogens, nutrients, organics, suspended solids and toxicants) of the water to be used for irrigation are flexible and negotiable, as these depend, among other things, on the crops to be grown; the irrigation technique and water management to be applied; the further crop handling; as well as the acceptability and perception of farmers and consumers.

- The location of the treatment plant would be defined in relation to the availability of suitable agricultural field, assumed to be available in the immediate peri-urban areas. This would reduce costs of effluent transport.

- Optimizing the location of the treatment plant vis a vis agricultural fields would in many cases require a policy of decentralization. This leads to an overall reduction of the length and size of the sewerage system and would allow a better control of the wastewater inflow, excluding e.g. toxic industrial waste streams into the system.

- To solve the mismatch between effluent supply and irrigation water demand, effluent storage in the irrigation system is needed, which should also be considered for its role as post-treatment step. 
- Knowing the benefits of effluent use determines to a large extent the economic affordability with respect to the required infrastructure and the acceptable costs per volume of treated sewage.

- Downstream productive use should lead to a policy of separating waste streams avoiding the mixing of black water with large amounts of relatively clean waters.

Using a reverse water chain approach would imply intensive discussions and negotiations between all stakeholders concerned. In such a process other possible interventions might be identified in addition to the wastewater treatment process, with the aim to reduce overall costs and to fully access the available resources, while reducing uncontrolled discharges into the environment. Subsequently, related costs can be spread across different stakeholders.

\section{Pathogen handling in a reverse water chain approach}

Contamination of agricultural products by pathogenic organisms is considered to be one of the major risks in effluent use. The generally accepted approach is to treat the wastewater up to levels at which the contamination potential is practically eliminated. Consequently, high-cost advanced wastewater treatment systems are required. In practice, such extensive pathogen removal efficiency is hardly ever realized in developing countries. However, by analyzing the route from the cultivation of the crop into the household, various levels of interception can be distinguished showing that pathogen removal and pathogenic contamination do not necessarily have to be addressed by advanced treatment alone (WHO 2006) but can also be made at the stages of crop handling, crop selection and irrigation.

\section{Crop handling}

Using clean irrigation water does not give a guarantee that a crop is free of pathogens when sold (Amoah et al. 2005), as also crop handling is a potential source of contamination. This is particularly true in less prosperous countries where numerous sources of infection are apparent. Safe handling requires knowledge transfer and education of farmers, field labourers, transporters and merchants as well as consumer.

\section{Crop selection}

Depending on the quality of the effluent to be used, the crops to be cultivated can be selected by degree of wastewater contact, in which the highest degree of purification is required for crops that are in full contact with the irrigation water and those that are eaten raw (WHO 2006).

\section{Irrigation water management}

Pathogen-rich wastewater should be handled with care to avoid direct contact by farm labourers and people in the vicinity. Use of sprinkler irrigation is discouraged as pathogen loaded droplets (aerosols) may drift over large distances. On the other hand, irrigation techniques such as drip irrigation limit the contact between the wastewater and the irrigators and crops. 
The field could also be used for disinfection, for example by fixing a required minimum period between the last irrigation and the crop harvesting. In this way UV-sunlight and fielddrying are used as means to reduce the pathogen levels on the crops (Pescod 1992), although this does not apply to the more persistent cysts and the helminths ova or worm eggs.

Irrigation scheme

After treatment, the water is distributed to an irrigation network. For operational reasons, in order to regulate peak demands as well as fluctuations in effluent flow, the irrigation network should be preceded by a storage facility. This allows for an optimal use of the effluent and nutrients (Darwisch et al. 2007). Such a reservoir could be combined with pathogen removal, reducing the costs for the overall layout. Disinfection taking place in such reservoirs include settling of helminth ova and natural decay of pathogenic organisms. In addition, low amounts of chemicals or other disinfection methods could be used.

Access to fresh water in addition to the effluent creates the possibility for blending different water qualities, an excellent water management technique not only to balance the water demandsupply ratio, but also to lower concentrations of pathogens, along with nutrients, and salts.

\section{Treatment technology}

Disinfection of wastewater could be part of the applied treatment technology. Considering the negative impact of chlorine; the formation of persistent carcinogenic chlorinated organic compounds, other methods such as ultraviolet (UV) radiation, titanium oxide $\left(\mathrm{TiO}_{2}\right)$ and membranes should be used in order to reduce the pathogen load. Particularly when treatment plants do not deliver high quality effluents, chlorination deteriorates the quality rather than improving it. Re-growth of indicator organism in the effluents has also been observed (WERSC, University of Jordan, unpublished).

It must be noted that advanced pathogen removal, is generally a very costly part of the treatment scheme. A more cost-effective approach is to integrate field-pathogen removal as discussed in the crop handling subsection with removal of persistent cysts and helminth ova in the treatment plant. Helminth ova are relatively big and can be removed from the water using techniques such as settling and filtration using packed beds or upflow anaerobic sludge blanket systems (Von Sperling and de Lemos Chernicharo 2005; Jimenez 2007).

\section{Sanitation system}

The general concept adopted in industrialised countries is flush-through toilets, which are connected to the sewerage network. In this way, the concentrated hazardous waste (human faeces) is diluted by a factor of 100-200 or more, creating an immense pool of diluted infectious wastewater. This will get worse if urban runoff is also conveyed with the same system. Instead of combined sewage systems, the introduction of source separated sewerage, where the black (toilet) water is separated from the rest, will result in grey wastewater which is relatively easy to treat and which contains several million fewer pathogens. Particularly in new housing estates, hotels, hospitals, and recreational areas, source separating sewer systems are relatively easy to construct, yet hardly implemented.

The previous analysis illustrates that by following an integrated approach, constraints related to the use of sewage effluents in irrigated agriculture can be dealt with at various locations in the water chain. Such an approach can also be applied to other compounds of concern like nutrients, micro-pollutants and salts. 


\section{Wastewater treatment for effluent use in irrigated agriculture}

Following a reverse water chain approach, the selection of the most appropriate treatment method, with the aim to use the effluent as irrigation water, would follow other criteria than the conventional approach. The following criteria are of importance, the weight of which is dependent on the local socio-economic situation:

\section{Cost effectiveness}

The availability of cost-effective treatment systems will increase the accessibility of sewage as a water and nutrient resource and will reduce the need for farmers to use raw sewage in agriculture. Obviously, the costs for the required investments are a community burden and can never be absorbed by the poor farmers that now use the raw sewage. However, by implementing an integrated approach, a shared cost concept could lead to a feasible solution. Alternatively, a private company could take the delegated responsibility for wastewater treatment, charging treatment fees to the citizens and water supply fees to the farmers. Long-term depreciation periods, soft loans and government regulations are tools for preventing excessive fees for either citizens or farmers. Obviously, implementation and control of sewage treatment requires a well-developed institutional framework, irrespective of the type of technology that is applied.

\section{Compactness}

An important advantage of compact systems is the possibility to construct the treatment in the vicinity of the populated area, preventing the need for expensive conveyance networks and improving control over the origin of wastewater flows. Surface systems such as pond systems, constructed wetlands, and slow sand filtration require large areas of land and thus are constructed at some distance from the city, where land is cheaper. This distance is also required to avoid odour problems in the urban area. From an agricultural point of view, it is obvious that direct evaporation from pond systems, which could count for $15 \%$ or more of design inflow in hot climates, and a concomitant increase of the salt concentration leads to poorer quality water. On the other hand, the surface systems do have their advantages as cheap post-treatment, or as part of the effluent storage capacity, so should be considered if location permits.

\section{Robustness}

A treatment system must be reliable for all circumstances. Irregularities in flow and load should not disturb the processes of the selected treatment system. In addition, the dependence on infrastructure investments, such as electricity supply, should be as low as possible. Also, the costs of electricity could be prohibitive, because in developing countries the availability of electricity supply is not always guaranteed 24 hday $^{-1}$. The same is true for regions in conflict.

\section{Flexibility}

It is not very likely that at present developing countries will be in the position to copy "Western standards" and treatment capacity when developing and implementing their local policy. Probably a similar approach will, and needs to be, followed as we have seen in the 
industrialised world. This means, a gradual increase of discharge standards allowing the implementation of basic treatment first, followed by a gradual extension of the treatment plant to more stringent legislation. It is well known that the removal of $80 \%$ of the pollution load can be obtained with limited costs, while the costs for the removal of the last $20 \%$ does not merit its purpose if in the same region raw sewage is discharged owing to limited availability of funds. But the chosen system must allow future extension to more stringent legislation.

\section{Acceptability}

The technology to be applied, with clear reference to affordability, must be accepted by the various stakeholders involved, including the executing institutions, responsible engineers, local community and farmers, as this will guarantee the sustainability of the investment. Often a discrepancy is observed between the wishes of responsible institutions and community members, and the capabilities of the local community, particularly in donor projects where technology-push is a consequence of a supply driven set-up of a project.

\section{Decentralisation}

As the generally applied "Western" concept is based on centralised services, huge infrastructure investments are required. For developing countries, the construction of extensive sewerage networks is absolutely out of the question, forcing a change in conceptual thinking. In a decentralised approach, a city, region, or country can be served with sanitation and treatment step by step, without the need to firstly accomplish a regional infrastructure investment. In this sense, decentralisation will immediately increase the accessibility of sewage as an alternative water and nutrients resource, even within the urban context. Moreover, the decentralised approach provides a means to exclude heavily polluted wastewaters from industrial estates from the domestic wastewaters collected. Industrial discharges may severely limit the applicability of treated wastewaters in the agricultural field owing to the presence of heavy metals, toxic compounds, persistent organics, salts, among other constituents.

The decentralised set-up, using satellite gravity sewers in a single catchments area, can be constructed using low cost sewerage systems. For instance, smallbore sewers connected to (available and improved) septic tanks, now considered to be constructed in Bonaire (Haverkamp 2009), offer a cost-effective solution for primary wastewater treatment combined with conveyance to a collection point. A compact decentralised post-treatment, such as a trickling filter, may then upgrade the effluent quality until the required standards for (restricted) irrigation. From the water distribution point of view, decentralisation has the advantage of limited conveyance of the treated water as well. A small collection area also implies a small distribution system after treatment. The latter can be more easily combined with peri-urban farming systems.

\section{Location}

In order to avoid the need for large conveyance networks for the treated water, the treatment systems should, ideally, be constructed closer to agricultural fields where the treated water will be used. In the conventional civil engineering point of view, treatment systems are generally located at the lowest point, which, in coastal areas, is near to the sea (Australia!) where there are no agricultural activities. This is particularly the case in a centralised set-up of the master-management plan e.g. in the case of Tunisia (Chenini et al. 2003). 
Management plan

For the sake of sustainable development, a master-management plan must underlie the individual projects. In considering a decentralised set-up, such a management plan might look more complex, but could also be developed stepwise. An interesting reference is the city of Recife, Brazil that several years ago adopted the decentralised approach, including decentralised wastewater treatment as the most feasible alternative in their specific situation (Florencio and Kato 2001).

\section{Discussion}

A reverse water chain approach is a new concept of wastewater management and offers interesting perspectives for economising the urban water chain. In eThekwini, South-Africa, such approach is being tried out in a collaborative effort between municipality, its agricultural management unit, consultants, farmers and research institutions aiming to develop an alternative for the unsuccessful top-down approach applied before (pers. comm. Chris Buckley and Wolf Raber). In contrast to the generally applied approach, the ultimate users, i.e. peri-urban farmers, set the criteria for designing the urban water flows. Separation of black toilet waters from the other wastewater streams and decentralised collection, to avoid the inclusion of industrial wastewater, will more easily facilitate the use of the treated water in agriculture. Moreover, treatment systems would be located nearer to the agricultural fields and can be simplified if the fields are incorporated in the overall treatment scheme. In return, farmers can benefit from the available water and nutrients to produce the crops. Whether or not this is acceptable depends on the local situation and the socio-economic conditions of the farmers.

Open Access This article is distributed under the terms of the Creative Commons Attribution Noncommercial License which permits any noncommercial use, distribution, and reproduction in any medium, provided the original author(s) and source are credited.

\section{References}

Amoah P, Drechsel P, Abaidoo RC (2005) Irrigated urban vegetable production in Ghana: sources of pathogen contamination and health risk elimination. Irrig Drain 54:S49-S62

Asano T (ed) (1998) Wastewater reclamation and reuse. Water quality management library, Vol. 10. Technomic Publishing Company, Inc, Lancaster

Blumenthal UJ, Peasy A (2002) Critical review of epidemiological evidence of the health effects of wastewater and excreta use in agriculture. Unpublished document prepared for WHO, Geneva (available on request), $40 \mathrm{pp}$

Boom S, Huibers FP, van Lier JB (2007) Wastewater irrigation in Jordan: a mismatch in macro nutrient provision. Water Practice and Technology, 3(2): doi:10.2166/wpt.2008.042

Bots PWG (2008) Benchmarking in Dutch urban water management: an assessment. Adaptive and Integrated Water Management: 277-300

Chenini F, Huibers FP, Agodzo SK, Van Lier JB, Duran A (2003) Use of wastewater in irrigated agriculture. Country studies from Bolivia, Ghana and Tunisia. Vol. 3: Tunisia. Wageningen: Wageningen Universiteit, IWE (W4F-Wastewater), pp 52 
Darwisch MR, Sharara M, Sidahmed M, Haidar M (2007) The impact of a storage facility on optimality conditions of wastewater reuse in land application: a case study in Lebanon. Resour Conserv Recycl 51:175-189

Florencio L, Kato MT (2001) Perspectives of anaerobic treatment for domestic sewage in Recife Metropolitan Region. In: van Lier JB, Lexmond M (eds), Anaerobic digestion for sustainable development. Proc. Int. Farewell Seminar of Prof. Gatze Lettinga, 29-30 March 2001, Wageningen, The Netherlands

Haverkamp Y (2009) Water and wastewater in the Caribbean. An overview of the current and future water and wastewater situation on the Caribbean islands. Wageningen University, unpublished MSc-thesis

van der Hoek W (2004) A framework for a global assessment of the extent of wastewater irrigation in developing countries: health effects and technical solutions. Technical Paper No. 51. World Bank, Washington DC, USA

Huibers FP, van Lier JB (2005) Use of wastewater in agriculture: the water chain approach. Irrig Drain 54: S3-S9

Jimenez B (2007) Helminth ova removal from wastewater for agriculture and aquaculture reuse. Water Sci Technol 55(1-2):485-493

Kassab GH, Koetse E, van Lier JB (2007) Integrating methanogenesis and denitrification in EGSB reactors for adjusting effluent nitrogen level. In: Proc. of 6th IWA Specialist Conference on Wastewater reclamation and reuse for sustainability, Antwerp, Belgium, October 9-12, 2007

Martijn E-J, Huibers FP (2001) Use of treated wastewater in irrigated agriculture. Treated wastewater characteristics and implications. CORETECH Working document WP4-1: 34 pp. ISBN: 90-6754-649-6

Pescod MB (1992) Wastewater treatment and use in agriculture. Irrigation and Drainage Paper 47, Food and Agriculture Organization, Rome

Rose JB (2007) Water reclamation, reuse and public health. Water Sci Technol 55(1-2):275-282

Shuval H, Lampert Y, Fatal B (1997) Development of a risk assessment approach for evaluating wastewater reuse standards for agriculture. Water Sci Technol 35(11-12):15-20

Stichting Rioned (2006) Riool in Cijfers, 2005-2006. Periodic report (in Dutch). Available on internet via: http:/www.riool.net/riool/binary/retrieveFile?instanceid=20\&itemid=61\&style=default

Van Lier JB (2008) High-rate anaerobic wastewater treatment: diversifying from end-of-the-pipe treatment to resource oriented conversion techniques. Water Sci Technol 57(8):1137-1148

Von Sperling M, de Lemos Chernicharo CA (2005) Biological wastewater treatment in warm climate regions. IWA, London. ISBN 1843390027

WHO (1989) Health guidelines for the use of wastewater in agriculture and aquaculture. Technical report series 778. World Health Organisation, Genève, Switzerland

WHO (2006) Guidelines for the safe use of wastewater, excreta and grey water, vol. 2. Wastewater use in agriculture. World Health Organisation, Genève, p 213 